\title{
Preferential Mesenteric Fat Accumulation and Enhanced Portal Free Fatty Acid Delivery in a High-Carbohydrate Diet Fed Rats
}

\author{
Yoko Shirai and Masashige Suzuki* \\ Laboratory of Exercise and Nutrition, Institute of Health and Sport Sciences, University of Tsukuba, \\ Tsukuba 305-8574, Japan
}

Received 1 August, 2002; Accepted 4 September, 2002

\begin{abstract}
Summary The regulation of adipose tissue distribution is an important problem in view of the close epidemiological and metabolic associations between centralized fat accumulation and disease. However, the majority of studies concerning adipose tissue distribution and metabolic disorders have focused on subjects already being obese. In this study, the effects of a high-carbohydrate diet (CHO) and a high-fat diet (FAT) on mass and function of mesenteric adipose depot, drained by the mesenteric vein, was examined in the pre-obese rat model. After 4 weeks of iso-energy feeding, the ratio of mesenteric adipose tissue weight to non-mesenteric was significantly greater in the CHO-fed group than in the FAT-fed group. Incorporation of orally administrated ${ }^{3} \mathrm{H}$-glucose into the mesenteric depot was more rapid in the CHO-fed group than in the FAT-fed group, but its incorporation into the non-mesenteric depot was similar between the two dietary groups. Arterial and mesenteric concentrations of free fatty acid and triglyceride of the $\mathrm{CHO}$-fed group were significantly higher than those of the FAT-fed group. Gene expression of PPAR- $\gamma$ and UCP-2 was similar among adipose depots, and there was no significant difference between the two dietary groups. In conclusion, dietary carbohydrate was preferentially incorporated into the total lipid in mesenteric adipose tissue. Without an increase in total body fat, $\mathrm{CHO}$ feeding for 4 weeks reinforces incorporation of dietary glucose into mesenteric depot, resulting in an increases of relative mesenteric adipose mass and portal FFA delivery.
\end{abstract}

Key Words: mesenteric fat, portal free fatty acid, dietary carbohydrate, lipogenesis

\section{Introduction}

The detrimental influence of abdominal obesity on the metabolic process is mediated by excessive visceral fat deposition. Excess visceral fat, independent of overall obesity, is associated with higher plasma levels of glucose and insulin, hyperlipidemia, and decreased HDL cholesterol concentrations, compo-

\footnotetext{
*To whom correspondence should be addressed. Present address: School of Sport Sciences, Waseda University, Nishi-Tokyo 202-0021, Japan

Tel \& Fax: +81-42-461-1241

E-mail: suzuki-dumbbell@waseda.jp
}

nents of insulin resistance syndrome, and constituting a cluster of risk factors for atherosclerotic cardiovascular disease [1].

In the abdominal cavity, several discrete adipose tissues exist. Due to its unique anatomical location, mesenteric adipose tissue, which is drained by the portal vein, distinguished from other adipose depots. Lipolysis in mesenteric adipose tissue exposes liver to a high concentration of free fatty acid (FFA) and is assumed to be the cause of metabolic disorders, such as glucose intolerance and hyperlipidemia, seen in visceral obesity. Since mesenteric adipose tissue resides next to gastrointestinal tract, it is more susceptible to influence by paracrine regulators from gastrointestinal tract [2-5]. 
Among dietary factors, high sucrose intake is a candidate for inducing mesenteric fat accumulation. High sucrose loading increases mesenteric fat both in ventromedial hypothalamus-lesioned obese and sham-operated rat [6]. Since mesenteric adipose tissue shows an abundant blood flow, in comparisons with other depots [7], it is conceivable that the mesenteric fat receives more nutrients delivery. Although anatomical considerations suggest an importance of mesenteric adipose tissue exposing liver to high concentration of FFA, nothing is known about portal FFA delivery itself, particularly in animal during fat accumulation.

In addition, recent evidence points out to the fact that obesity is a related to disturbance of gene expression homeostasis [8,9]. Particularly, an altered expression of several transcription factors, including peroxisome proliferator-activated receptors (PPARs), and others, such as uncoupling protein (UCP), could be involved in the development of obesity $[10,11]$. Although PPARs mRNA is expressed very early in the course of adipocyte differentiation in vitro [12, 13], there is a paucity of literature examining the physiological regulation, such as an effect of dietary composition of PPARs gene expression among adipose tissues in vivo. Characterization of the physiological regulation of PPARs gene expression in altered physiological states, including dietaryinduced visceral obesity, seems to be critical.

In the present study, we investigated 1) incorporation of orally administered glucose into total lipid of adipose tissue, 2) body fat accumulation, 3) portal FFA delivery, and 4) gene expression of PPAR- $\gamma$ and UCP-2, the dominant subtypes of PPAR and $\mathrm{UCP}$ in adipocytes, in rats accumulating mesenteric fat mass by dietary manipulation.

\section{Materials and Methods}

\section{Materials}

d- $\left[2-{ }^{3} \mathrm{H}\right]$ glucose was purchased from Amersham Pharmacia Biotech Ltd. (NJ, USA); ACSII, a liquid scintillation cocktail, from DuPont (DE, USA); ISOGEN, a total RNA isolation solution and ethidium bromide, from Nippon Gene Co. Ltd. (Tokyo, Japan); and Z-Taq polymelase and agarose, from TAKARA SHUZO Co. Ltd. (Tokyo, Japan). PCR primers were synthesized at the BEX Co. Ltd. (Tokyo, Japan). All other chemicals were purchased from Wake Pure Chemical Industries Ltd. (Tokyo, Japan).
Table 1. Composition of experimental diets.

\begin{tabular}{|c|c|c|c|c|}
\hline Ingredient & \multicolumn{2}{|c|}{$\mathrm{CHO}$} & \multicolumn{2}{|c|}{ FAT } \\
\hline & (g) & (kcal) & (g) & (kcal) \\
\hline Casein & 172.52 & 652.14 & 228.20 & 862.60 \\
\hline L-Methionine & 2.63 & & 3.47 & \\
\hline Mineral mixture & 70.00 & & 92.00 & \\
\hline Choline bitartrate & 3.00 & & 3.94 & \\
\hline Vitamin mixture & 7.00 & & 9.20 & \\
\hline Cellulose & 50.00 & 16.82 & 50.00 & 22.11 \\
\hline Corn starch & 680.63 & $2,409.43$ & 411.95 & $1,458.30$ \\
\hline Safflower oil & 14.22 & 130.97 & 201.25 & $1,853.51$ \\
\hline \multirow[t]{2}{*}{ Total } & $1,000.00$ & $3,209.36$ & $1,000.01$ & $4,196.52$ \\
\hline & \multicolumn{4}{|c|}{ (\% of energy) } \\
\hline Fat & \multicolumn{2}{|c|}{5} & \multicolumn{2}{|c|}{45} \\
\hline Carbohydrate & \multicolumn{2}{|c|}{75} & \multicolumn{2}{|c|}{35} \\
\hline Protein & \multicolumn{2}{|c|}{20} & \multicolumn{2}{|c|}{20} \\
\hline & \multicolumn{2}{|c|}{100} & \multicolumn{2}{|c|}{100} \\
\hline
\end{tabular}

\section{Animals}

The experimental protocols for this study were approved by the Institutional Animal Care and Use Committee at the University of Tsukuba. Male Sprague-Dawley rats (4 weeks of age) were obtained from Nippon CLEA (Tokyo, Japan). Animals were housed in individual wire mesh cages in a temperature controlled $\left(22-24^{\circ} \mathrm{C}\right)$ room with a $12 \mathrm{~h}$ lightdark cycle and given water ad libitum. They were randomly divided into 2 groups; fed on a high-carbohydrate diet (protein/fat/carbohydrate $=20 / 5 / 75 \%$; $\mathrm{CHO}$ ) and a high-fat diet (protein/fat/carbohydrate $=20 / 45 / 35 \%$; FAT) for 4 weeks (Table 1 ).

\section{Incorporation of glucose into total lipid}

Each rat was lightly anesthetized with ethyl ether and given, through a stomach tube, a total of $5 \mu \mathrm{Ci}$ $(0.2 \mathrm{~g})$ of $\mathrm{d}-\left[2{ }^{3} \mathrm{H}\right]$ glucose in $1.0 \mathrm{ml}$ distilled water. Six rats were killed at each hour up to $4 \mathrm{~h}$ after the $\mathrm{d}-\left[2-{ }^{3} \mathrm{H}\right]$ glucose instillation. The rats were anesthetized with pentobarbital $(60 \mathrm{mg} / \mathrm{kg}$ body wt) and mesenteric and non-mesenteric (epididymal, perirenal and abdominal subcutaneous) adipose tissues were taken. Total lipids of adipose tissue were extracted according to the method of Folch et al. [14], and $1 \mathrm{ml}$ of organic phase were dissolved in 10 $\mathrm{ml}$ of scintillation cocktail and radioactivity was measured by automatic liquid scintillation spectrometer (Beckman LS6500, Tokyo, Japan).

\section{Plasma analysis}

Plasma FFA and triglyceride (TG) levels were determined with the Wako NEFA-C test kit and the Wake Triglyceride-G test kit, respectively. 
Determination of gene expression of PPAR- $\gamma$ and $U C P-$ 2

Total RNA was extracted from adipose tissues with a guanidium thiocynate-water saturated phenol extraction method using ISOGEN. First-strand cDNA synthesis was performed on $5 \mu \mathrm{g}$ total RNA using oligo (dT) as described in manufacturer's instructions (GIBCO-BRL Super Script Kit; Life Technologies, MD). We used primers 5'-CATAAAGTCCTTCCCGCTGA-3' and 3'-GAAACTGGCACCCTTGAAAA-5' for amplification of the PPAR- $\gamma$, 5'-ATGACAGACGACCTCCCTTG-3' and $3^{\prime}$-GAAGGCATGAACCCCTTGTA$5^{\prime}$ for the UCP-2 and 5'-CCTAGCACCATGAAGATCAA-3' and $3^{\prime}$-AGCCATGCCAAATGTCTCAT- $5^{\prime}$ for the $\beta$-actin. The PCR reactions were carried out in a DNA thermal cycler (Perkin-Elmer, $\mathrm{NJ}$ ) using the following cycle conditions: initial denaturation at $98^{\circ} \mathrm{C}$ for $1 \mathrm{~min}$, denaturation at $98^{\circ} \mathrm{C}$ for $5 \mathrm{~s}$, annealing at $54^{\circ} \mathrm{C}$ (at $58^{\circ} \mathrm{C}$ in the case of $\beta$ actin) for $20 \mathrm{~s}$, and extension at $72^{\circ} \mathrm{C}$ for $20 \mathrm{~s}$. The PCR reactions were repeated for 26 cycles (for 18 cycles in the case of $\beta$-actin). PCR products $(10 \mu \mathrm{l})$ were analyzed by electrophoresis in 1\% agarose gels and ethidium bromide-stained. The amounts of mRNA in each sample were quantified by NIH image [35].

\section{Data analysis}

Values are expressed as the means \pm SEM. Differences among groups were determined using analysis of variance (ANOVA) followed by Fisher's protected least significant difference test (PLSD), and probability values of $<0.05$ were considered significant.

\section{Results}

\section{Body weight and adipose tissue weight}

Initial and final body weights were similar in the CHO- and the FAT-fed group. Weight of adipose depot, except mesenteric, tended to be heavier in the FAT-fed group than in the $\mathrm{CHO}$-fed group. However, the ratio of mesenteric adipose tissue weight to non-mesenteric one was significantly greater in the CHO-fed group compared with the FAT-fed group (Table 2).

\section{Tissue uptake of orally administered glucose}

Incorporation of ${ }^{3} \mathrm{H}$-labeled glucose to total lipid was greater in mesenteric adipose depot compared with non-mesenteric depot (Fig. 1). After 4 weeks of
Table 2. Food intake and body composition.

\begin{tabular}{lrc}
\hline & CHO & FAT \\
\hline Body weight $(\mathrm{g})$ & & \\
$\quad$ Initial & $84 \pm 1$ & $84 \pm 1$ \\
$\quad$ Final & $286 \pm 4$ & $292 \pm 5$ \\
Food intake (kcal/4 weeks) & $1,949 \pm 9$ & $1,956 \pm 12$ \\
Adipose tissue weight (g) & & \\
$\quad$ Mesenteric & $3.82 \pm 0.16$ & $3.38 \pm 0.21$ \\
$\quad$ Perirenal & $3.45 \pm 0.24$ & $4.02 \pm 0.25$ \\
Epididymal & $3.76 \pm 0.11$ & $3.88 \pm 0.18$ \\
$\quad$ Subcutaneous & $12.16 \pm 0.74$ & $13.33 \pm 0.90$ \\
Total body fat (\%) & $8.02 \pm 0.34$ & $8.40 \pm 0.43$ \\
Mesenteric/non-mesen- & $0.19 \pm 0.01^{*}$ & $0.16 \pm 0.01$ \\
$\quad$ teric ratio & & \\
\hline * $p<0.05$ & & \\
\end{tabular}

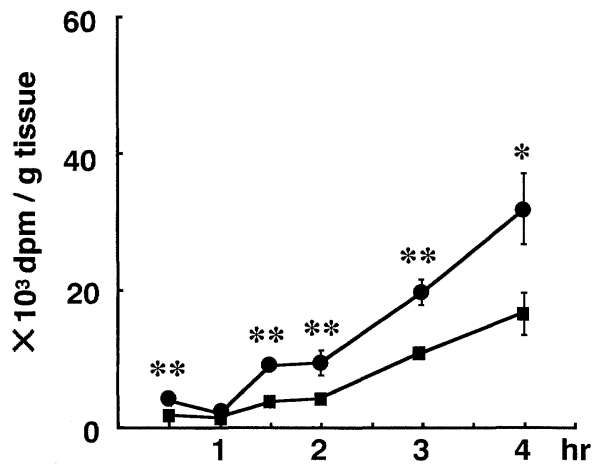

Fig. 1. Incorporation of orally administered glucose into total lipid of mesenteric ( $)$ and non-mesenteric adipose tissue ( $\mathbf{\square}$; perirenal, epididymal and subcutaneous). Accumulation of radioactivity in total lipid of adipose tissues was measured at $0.5,1.0$, $1.5,2.0,3.0$, and $4.0 \mathrm{~h}$ after administration of ${ }^{3} \mathrm{H}-$ glucose. **** Significantly different from nonmesenteric adipose tissue $(p<0.05, p<0.01)$.

dietary manipulation, this regional difference in nutrient incorporation remained. Incorporation of labeled glucose into mesenteric depot was greater in the CHO-fed group than that of the FAT-fed group, but that into non-mesenteric depot was similar between the two dietary groups (Fig. 2).

\section{Plasma FFA and TG}

Arterial and portal concentration of FFA and TG were significantly greater in the $\mathrm{CHO}$-fed group than in the FAT-fed group. Portal-arterial difference in FFA concentration was also greater in the CHOfed group than in the FAT-fed group, while TG level was similar between arterial and portal blood (Fig. 3). Portal FFA was positively correlated with arterial TG $\left(r^{2}=0.754, p<0.0001\right)$ (Fig. 4). 


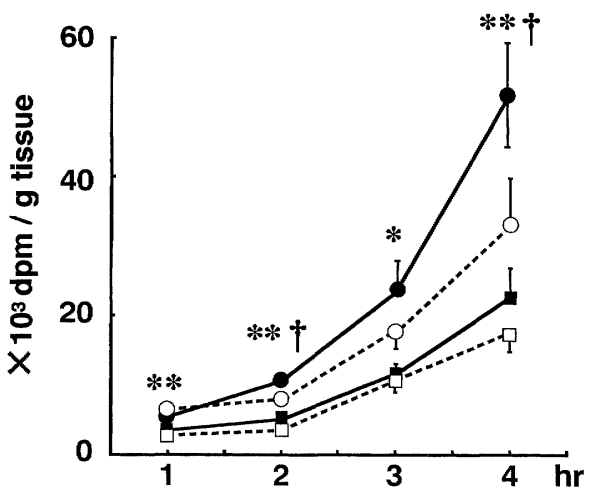

Fig. 2. Incorporation of orally administered glucose into total lipid of mesenteric $(\bullet, O)$ and non-mesenteric $(\square, \square)$ adipose tissues after 4 weeks of $\mathrm{CHO}$ and $\operatorname{FAT}(O, \square)$ diet. ${ }^{* * * *}$ Significantly different from non-mesenteric adipose tissue $(p<0.05$, $p<0.01$ ); ${ }^{\dagger}$ Significantly different from adipose tissue of FAT-fed animals $(p<0.05)$.
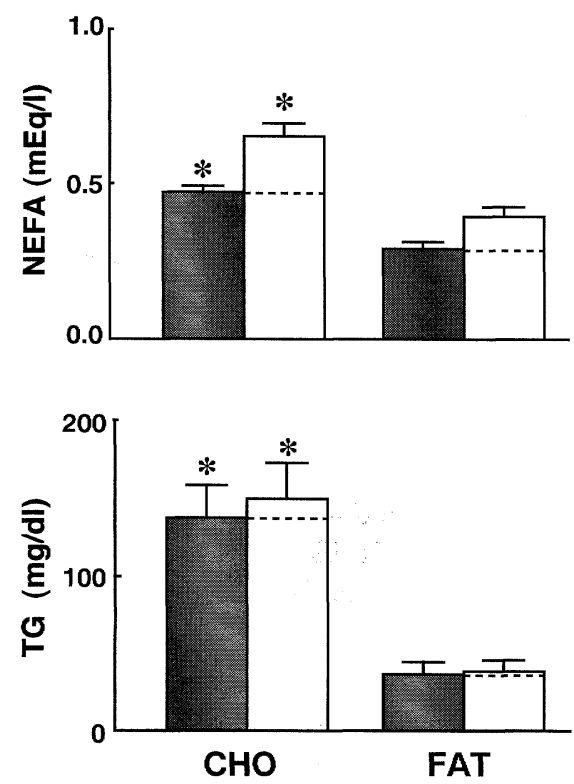

Fig. 3. Plasma FFA and TG concentration in artery and portal vein. FFA (upper panel) and TG (lower panel) concentration in arterial (closed bar) and portal vein (open bar) were shown. Portal-artery difference, shown as above the dotted line, in FFA was significantly greater in $\mathrm{CHO}$-fed rats $(0.21 \pm 0.03 \mathrm{mEq} /$ liter $)$ than those of FAT-fed rats $(0.11 \pm 0.02 \mathrm{mEq} /$ liter $)(p<0.05)$. Portal-artery difference in TG was similar in the two dietary groups. * Significantly different from FAT-fed group $(p<0.05)$.

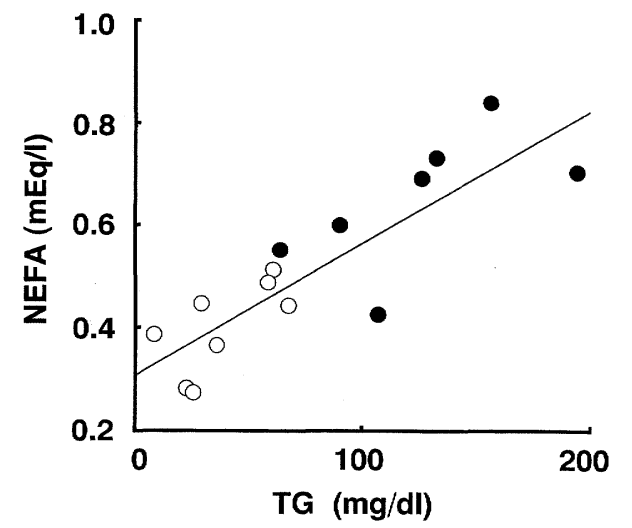

Fig. 4. Relation between arterial TG and portal FFA concentration (CHO: •, FAT: O) $r^{2}=0.754, p<$ 0.0001 .
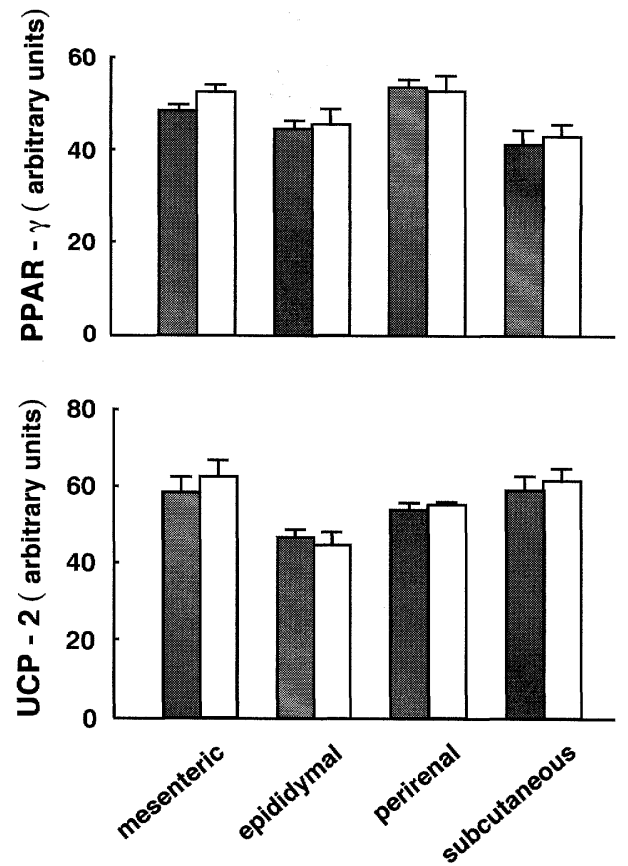

Fig. 5. Gene expression of PPAR- $\gamma$ and UCP-2 in adipose tissues. mRNA level of PPAR- $\gamma$ (upper panel) and UCP-2 (lower panel) in adipose tissues of $\mathrm{CHO}$-fed rats (closed bar) and FAT-fed rats (open bar) were shown. 


\section{Gene expression}

Gene expression of PPAR- $\gamma$ and UCP-2 was similar among adipose depots, and there was no significant difference between the two dietary groups (Fig. $5)$.

\section{Discussion}

Epidemiological studies suggest that increasing dietary fat content promotes greater body fat accumulation through excess energy intake [15-17]. When the energy intake of the CHO-fed and FATfed group was identical, adipose tissue weights in the two groups were comparable. Interestingly, mesenteric adipose tissue of the $\mathrm{CHO}$-fed group tended to be heavier $(p=0.107)$, while non-mesenteric adipose tissues tended to be lighter $(p=0.111-0.572)$, than those of the FAT-fed group. The increased ratio of mesenteric adipose tissue weight to non-mesenteric depots in the $\mathrm{CHO}$-fed group suggests that nutrients in the carbohydrate diet were preferentially accumulated in mesenteric adipose tissue.

Orally administered glucose was incorporated into total lipid of adipose depots and the rate was faster in mesenteric depot than that in non-mesenteric (Fig. 1). After 4 weeks of dietary manipulation, incorporation rate of glucose into total lipid in mesenteric fat was higher in the $\mathrm{CHO}$-fed group than in the FAT-fed group while that of non-mesenteric depot was similar between the two dietary groups. Thus, enhanced nutrient uptake of mesenteric adipose depot was reinforced by $\mathrm{CHO}$-feeding.

The enlargement of mesenteric fat, expressed as a ratio of mesenteric to non-mesenteric depot, was small (Table 2); however, it probably causes hyperlipidemia seen in the $\mathrm{CHO}$-fed group. FFA concentrations in portal and arterial blood were significantly higher in the CHO-fed group than in the FAT-fed group (Fig. 3). Further, portal-arterial difference in FFA concentration, surrogates of portal FFA delivery from mesenteric fat, was also significantly greater in the CHO-fed group. Portal FFA was positively correlated with arterial TG in the present study, suggesting that enhanced portal FFA levels stimulates the secretion of very low density lipoprotein from the liver consisting with observations in already obese human and animal [18]. FFA may also affect hepatic clearance of insulin [19]. The consequence would be peripheral hyperinsulinemia, which is further amplified by increased insulin production known to occur in obesity in general [18]. In the present study, the increase in the mesenteric fat mass in the CHO-fed group was still small, and fasting insulin and glucose levels between the two dietary groups were comparable (data not shown). The question remains whether prolonged period of $\mathrm{CHO}$ feeding results in hyperinsulinemia and insulin resistance.

Greater arterial-portal difference in FFA concentration suggests a possibility that the intracellular concentration of FFA in mesenteric fat of the CHOfed group is higher than that of the FAT-fed group. Fatty acids have been shown to act as a signalling molecule that binds, activates $[20,21]$ and up-regulates [22] a new class of nuclear receptors, PPARs. PPAR $-\gamma$ is particularly interesting because it may link fatty acids with a program of gene expression involved in lipid storage and metabolism, including UCP-2 [23-25]. Altered expression of several transcription factors, including PPAR- $\gamma$ is assumed to be involved in the development of obesity [10]. Further, very recent study reported intrinsic differences in the characteristics of adipocyte from different depot [26, 27]. We therefore investigated whether a nutrientsensing pathway is different among adipose depot and influenced by dietary manipulation. However, gene expression of PPAR- $\gamma$ and UCP- 2 was similar among adipose depots and was not significantly different between the dietary groups (Fig. 5). Considering observations that mRNA level of PPAR- $\gamma$ in adipose tissue of weaning rats was not influenced by diet composition [28], PPAR- $\gamma$ appears not to be qualitatively regulated by nutritional condition per se, but it is up-regulated when mesenteric adipose depot severely expands.

The present study demonstrated that portal delivery of FFA in the CHO-fed group was enhanced after 4 weeks of feeding, even though their total body fat is less than that of the FAT-fed group and the increase in mesenteric adipose mass itself was minor $(p=0.18)$. Although the difference in metabolic characteristics among fat depots has not been fully elucidated, more remarkable changes in metabolism in the mesenteric fat than in non-mesenteric fat were observed when rats are exercise trained [29] or ventromedial hypothalamic-lesioned [30]. The enhanced portal delivery of FFA in the CHO-fed group can be explained by the possibilities that CHO intensified the following physiological and metabolic characteristics of mesenteric fat. First, mesenteric adipose tissue receives an abundant blood flow [7] and shows rapid TG turnover rate [31], in comparisons with other depots. Secondly, dietary 
intake, carbohydrate and fat in particular, stimulates sympathetic activity $[32,33]$, and noradrenalineinduced lipolytic response of mesenteric adipose tissue is greater than that of non-mesenteric adipose tissue [34]. Effect of CHO diet on blood flow, noradrenaline-induced lipolysis and cellularity of mesenteric depot, remains to be compared with those of non-mesenteric adipose tissues. Taken together, our findings showed that 1) more dietary glucose is incorporated into the total lipid of mesenteric depot than the non-mesenteric, 2) the relative mesenteric fat mass of the $\mathrm{CHO}$-fed group was greater than that of the FAT-fed group, when energy intake was matched, and 3) dietary glucose is associated with increased portal FFA delivery and its consequent hyperlipidemia. This enhancement of portal FFA level without leading to a corresponding increase in total body fat is significant since hepatic functions could be influenced by the delivery of portal FFA.

\section{Acknowledgments}

We wish to thank Mr. Tetsuo Koike (Health and Sports Sciences, University of Tsukuba, Ibaraki, Japan) for his technical assistance.

\section{References}

[1] Wajchenberg, B.L.: Subcutaneous and visceral adipose tissue: their relation to the metabolic syndrome. Endocr. Rev., 21, 697-738, 2000.

[2] Bragg, L.E., Thompson, J.S., and Rikkers, L.F.: Influence of nutrient delivery on gut structure and function. Nutrition, 7, 237-243, 1991.

[3] Tansy, M.F. and Kendall, F.M.: Gastrointestinal hormones and the quantitation of spontaneous duodenal motor activity. Toxicol. Pathol., 16, 118-122, 1998.

[4] Dowling, R.H.: Cellular and molecular basis of intestinal and pancreatic adaptation. Scand. J. Gastroenterol., 193, Suppl., 64-67, 1992.

[5] Miyawaki, K., Yamada, Y., Ban, N., Ihara, Y., Tsukiyama, K., Zhou, H., Fujimoto, S., Oku, A., Tsuda, K., Toyokuni, S., Hiai, H., Mizunoya, W., Fushiki, T., Holst, J.J., Makino, M., Tashita, A., Kobara, Y., Tsubamoto, Y., Jinnouchi, T., Jomori, T., and Seino, Y.: Inhibition of gastric inhibitory polypeptide signalling prevents obesity. Nat. Med., 8, 738-742, 2002.

[6] Keno, Y., Matsuzawa, Y., Tokunaga, K., Fujioka, S., Kawamoto, T., Kobatake, T., and Tarui, S.: High sucrose diet increases visceral fat accumulation in VMH-lesioned obese rats. Int. J. Obes., 15, 205-211, 1991.

[7] West, D.B., Prinz, W.A., and Greenwood, M.R.: Regional changes in adipose tissue blood flow and metabolism in rats after a meal. Am. J. Physiol., 257,
R711-716, 1989.

[8] Comuzzie, A.G. and Allison, D.B.: The search for human obesity genes. Science, 280, 1374-1377, 1998.

[9] Arner, P.: Obesity-a genetic disease of adipose tissue? Br.J. Nutr., 83, Suppl., 1, S9-16, 2000.

[10] Auwerx, J., Martin, G., Guerre-Millo, M., and Staels, B.: Transcription, adipocyte differentiation, and obesity. J. Mol. Med., 74, 347-352, 1996.

[11] Barsh, G.S., Farooqi, I.S., and O'Rahilly, S.: Genetics of body-weight regulation. Nature, 404, 644-651, 2000.

[12] Tontonoz, P., Hu, E., Graves, R.A., Budavari, A.1., and Spiegelman, B.M.: mPPAR gamma 2: tissue-specific regulator of an adipocyte enhancer. Genes. Dev., 8, 1224-1234, 1994.

[13] Chawla, A., Schwarz, E.T., Dimaculangan, D.D., and Lazar, M.A.: Peroxisome proliferator-activated receptor (PPAR) $\gamma$ : adipose-predominant expression and induction early in adipocyte differentiation. Endocrinology, 135, 798-800, 1994.

[14] Folch, J., Lees, M., and Sloane-Stanley, G.H.: A simple method for the isolation and purification of total lipids from animal tissues. J. Biol. Chem., 226, 497509, 1957.

[15] Romieu, I., Willett, W.C., Stampfer, M.J., Colditz, G.A., Sampson, L., Rosner, B., Hennekens, C.H., and Speizer, F.E.: Energy intake and other determinants of relative weight. Am. J. Clin. Nutr., 47, 406-412, 1988.

[16] Dreon, D.M., Frey-Hewitt, B., Ellsworth, N., Williams, P.T., Terry, R.B., and Wood, P.D.: Dietary fat:carbohydrate ratio and obesity in middle-aged men. Am. J. Clin. Nutr., 47, 995-1000, 1988.

[17] Klesges, R.C., Klesges, L.M., Haddock, C.K., and Eck, L.H.: A longitudinal analysis of the impact of dietary intake and physical activity on weight change in adults. Am. J. Clin. Nutr., 55, 818-822, 1992.

[18] Björntorp, P. and Brodoff, B.N.: Resional obesity, in Obesity, ed. by Björntorp, P., J. B. Lippincott Company, Philadelphia, pp. 579-586, 1992.

[19] Björntorp, P.: "Portal" adipose tissue as a generator of risk factors for cardiovascular disease and diabetes. Artheriosclerosis, 10, 493-496, 1990.

[20] Kersten, S., Desvergne, B., and Wahli, W.: Roles of PPARs in health and disease. Nature, 405, 421-424, 2000.

[21] Schoonjans, K., Staels, B., and Auwerx, J.: Role of the peroxisome proliferator-activated receptor (PPAR) in mediating the effects of fibrates and fatty acids on gene expression. J. Lipid Res., 37, 907-925, 1996.

[22] Nisoli, E., Carruba, M.O., Tonello, C., Macor, C., Federspil, G., and Vettor, R.: Induction of fatty acid translocase/CD36, peroxisome proliferator-activated receptor- $\gamma 2$, leptin, uncoupling proteins 2 and 3 , and tumor necrosis factor- $\alpha$ gene expression in human subcutaneous fat by lipid infusion. Diabetes, 49, 319-324, 2000.

[23] Camirand, A., Marie, V., Rabelo, R., and Silva, J.E.: 
Thiazolidinediones stimulate uncoupling protein-2 expression in cell lines representing white and brown adipose tissues and skeletal muscle. Endocrinology, 139, 428-431, 1998.

[24] Viguerie-Bascands, N., Saulnier-Blanche, J.S., Dandine, M., Dauzats, M., Daviaud, D., and Langin, D.: Increase in uncoupling protein-2 mRNA expression by BRL49653 and bromopalmitate in human adipocytes. Biochem. Biophys. Res. Commun., 256, 138-141, 1999.

[25] Aubert, J., Champigny, O., Saint-Marc, P., Negrel, R., Collins, S., Ricquier, D., and Ailhaud, G.: Up-regulation of UCP-2 gene expression by PPAR agonists in preadipose and adipose cells. Biochem. Biophys. Res. Commun., 238, 606-611, 1997.

[26] Tchkonia, T., Giorgadze, N., Pirtskhalava, T., Tchoukalova, Y., Karagiannides, L., Forse, R.A., DePonte, M., Stevenson, M., Guo, W., Han, J., Waloga, G., Lash, T.L., Jensen, M.D., and Kirkland, J.L.: Fat depot origin affects adipogenesis in primary cultured and cloned human preadipocytes. Am. J. Physiol., 282, R1286-1296, 2002.

[27] Caserta, F., Tchkonia, T., Civelek, V.N., Prentki, M., Brown, N.F., McGarry, J.D., Forse, R.A., Corkey, B.E., Hamilton, J.A., and Kirkland, J.L.: Fat depot origin affects fatty acid handling in cultured rat and human preadipocytes. Am. J. Physiol., 280, E238-247, 2001.

[28] Rousseau, V., Becker, D.J., Ongemba, L.N., Rahier, J., Henquin, J.C., and Brichard, S.M.: Developmental and nutritional changes of ob and PPAR $\gamma 2$ gene expression in rat white adipose tissue. Biochem. J., 321, 451-456, 1997.

[29] Shimomura, I., Tokunaga, K., Kotani, K., Keno, Y., Yanase-Fujiwara, M., Kanosue, K., Jiao, S., Funahashi,
T., Kobatake, T., Yamamoto, T., and Matsuzawa, Y.: Marked reduction of acyl-CoA synthetase activity and mRNA in intra-abdominal visceral fat by physical exercise. Am. J. Physiol., 265, E44-50, 1993.

[30] Matsuzawa, Y., Shimomura, I., Nakamura, T., Keno, Y., and Tokunaga, K.: Pathophysiology and pathogenesis of visceral fat obesity. Ann. N. Y. Acad. Sci. USA, 676, 270-278, 1993.

[31] Rebuffe-Scrive, M. and Björntorp, P.: Resional adipose tissue metabolism in man, in Metabolic Complications of Human Obesities, ed. by Vague, J., Elsevier Science Publishers, Amsterdam, pp. 149-159, 1985.

[32] Schwartz, J.H., Young, J.B., and Landsberg, L.: Effect of dietary fat on sympathetic nervous system activity in the rat. J. Clin. Invest., 72, 361-370, 1983.

[33] Rappaport, E.B., Young, J.B., and Landsberg, L.: Effects of 2-deoxy-D-glucose on the cardiac sympathetic nerves and the adrenal medulla in the rat: further evidence for a dissociation of sympathetic nervous system and adrenal medullary responses. Endocrinology, 110, 650-656, 1982.

[34] Van Harmelen, V., Lonnqvist, F., Therne, A., Wennlund, A., Large, V., Reynisdottir, S., and Arner, P.: Noradrenaline-induced lipolysis in isolated mesenteric, omental and subcutaneous adipocytes from obese subjects. Int. J. Obes. Relat. Metab. Disord., 21, 972979, 1997.

[35] Kakinuma, Y., Miyauchi, T., Kobayashi, T., Yuk, K., Maeda, S., Sakai, S., Goto, K., and Yamaguchi, I.: Myocardial expression of endothelin-2 is altered reciprocally to that of endothelin-1 during ischemia of cardiomyocytes in vitro during heart failure in vivo. Life Sci., 65, 1671-1683, 1999. 